\title{
Natural History of the Bruise: Formation, Elimination, and Biological Effects of Oxidized Hemoglobin
}

\author{
Viktória Jeney,, ${ }^{1,2}$ John W. Eaton,,3 György Balla,, ${ }^{1,4}$ and József Balla \\ ${ }^{1}$ Department of Medicine, University of Debrecen, Debrecen 4012, Hungary \\ ${ }^{2}$ MTA-DE Vascular Biology, Thrombosis and Hemostasis Research Group, Hungarian Academy of Sciences, Debrecen 4012, Hungary \\ ${ }^{3}$ Department of Medicine, James Graham Brown Cancer Center, University of Louisville, Louisville, KY 40059, USA \\ ${ }^{4}$ Department of Pediatrics, University of Debrecen, Debrecen 4012, Hungary
}

Correspondence should be addressed to Viktória Jeney; jeneyv@internal.med.unideb.hu

Received 28 February 2013; Accepted 12 April 2013

Academic Editor: Emanuela Tolosano

Copyright (C) 2013 Viktória Jeney et al. This is an open access article distributed under the Creative Commons Attribution License, which permits unrestricted use, distribution, and reproduction in any medium, provided the original work is properly cited.

\begin{abstract}
Numerous disease states are associated with hemolysis or hemorrhage. Because red cells in the extravascular space tend to lyse quickly, hemoglobin $(\mathrm{Hb})$ is released and is prone to autoxidation producing MetHb. Inorganic and organic peroxides may convert $\mathrm{Hb}$ and MetHb to higher oxidation states such as ferrylHb. FerrylHb is not a single chemical entity but is a mixture of globin- and porphyrin-centered radicals and covalently cross-linked $\mathrm{Hb}$ multimers. Oxidized $\mathrm{Hb}$ species are potent prooxidants caused mainly by heme release from oxidized $\mathrm{Hb}$. Moreover, ferrylHb is a strong proinflammatory agonist that targets vascular endothelial cells. This proinflammatory effect of ferrylHb requires actin polymerization, is characterized by the upregulation of proinflammatory adhesion molecules, and is independent of heme release. Deleterious effects of native $\mathrm{Hb}$ are controlled by haptoglobin (Hp) that binds cell-free $\mathrm{Hb}$ avidly and facilitates its removal from circulation through the CD163 macrophage scavenger receptor-mediated endocytosis. Under circumstances of $\mathrm{Hb}$ oxidation, $\mathrm{Hp}$ can prevent heme release from $\mathrm{MetHb}$, but unfortunately the Hp-mediated removal of $\mathrm{Hb}$ is severely compromised when $\mathrm{Hb}$ is structurally altered such as in ferrylHb allowing deleterious downstream reactions to occur even in the presence of $\mathrm{Hp}$.
\end{abstract}

\section{Introduction}

The red cell is usually a blessing but sometimes a curse. The normal red cell efficiently binds oxygen from the atmosphere, delivers it to the tissues, and helps remove the product of metabolic combustion, carbon dioxide. Nice. But the same cells can be involved in pathophysiologic mischief upon hemorrhage or intravascular hemolysis. Once outside the vascular system, red cells quickly burst releasing free hemoglobin $(\mathrm{Hb})$. That $\mathrm{Hb}$ is prone to spontaneous oxidation (as the scientists trying to develop Hb-based blood substitutes have repeatedly discovered). Even worse, the $\mathrm{Hb}$ may be converted to higher oxidation states such as ferrylHb which have potent proinflammatory and prooxidant effects, either directly or via the release of heme which itself is highly prooxidant. Here, we briefly describe what is known regarding the natural mechanisms which have evolved to control this cell-free hemoglobin and what is being learned about the biologic effects of $\mathrm{Hb}$ once it is released from the red cell in pathologic states.

\section{Antioxidant Network of Erythrocytes}

Hemoglobin $(\mathrm{Hb})$ autoxidation is the main source of reactive oxygen species inside erythrocytes. Taking into consideration the high intraerythrocytic concentration of $\mathrm{Hb}$-around $5 \mathrm{mM}$ as tetramer-even a slow rate of autoxidation could generate substantial amounts of ROS. To cope with this challenge, erythrocytes are equipped with highly effective antioxidant defenses [1]. This system includes enzymes such as $\mathrm{Cu} / \mathrm{Zn}$ superoxide dismutase (SOD1) that convert superoxide anion to hydrogen peroxide $\left(\mathrm{H}_{2} \mathrm{O}_{2}\right)$, catalase (Cat), glutathione peroxidase (Gpx-1), and peroxiredoxins (Prdxl and $\operatorname{Prdx} 2$ ) which decompose $\mathrm{H}_{2} \mathrm{O}_{2}$ to $\mathrm{H}_{2} \mathrm{O}$. Nonenzymatic scavengers such as glutathione also contribute to this protection. 
Gene knock-out mouse models have been used to estimate the relative importance of these antioxidant defenses. Surprisingly, under steady-state conditions, mice deficient in either Gpx-1 [2] or Cat [3] have a normal phenotype. However, Cat seems to be essential for protection against elevated levels of $\mathrm{H}_{2} \mathrm{O}_{2}$ since Cat deficient erythrocytes are very sensitive to exogenous $\mathrm{H}_{2} \mathrm{O}_{2}$ [4]. It has been suggested that erythrocyte Cat might function as a "sink" for extra-erythrocytic $\mathrm{H}_{2} \mathrm{O}_{2}$ and thus protect somatic cells against exogenous oxidant challenge [5]. In contrast to $\mathrm{Gp} \mathrm{I}^{-/-}$or $\mathrm{Cat}^{-/-}$ mice, $\operatorname{Pr} d x 1^{-/-}, \operatorname{Pr} d x 2^{-/-}$, and SOD1 $1^{-/-}$mice exhibit impaired erythrocyte antioxidant defense. As a result, concentrations of ROS are elevated and accompanied by hemolytic anemia in $\mathrm{SODI}^{-/-}$[6], $\operatorname{Prdx1^{-/-}}$ [7], and $\operatorname{Prd} x 2^{-/-}$mice [8].

The idea that $\mathrm{Hb}$ itself may have antioxidant properties and thus contribute to the antioxidant network of erythrocytes emerged recently. For example, the $\mathrm{Hb} \beta 93$ cysteine ( $\beta$ 93Cys) - highly conserved in vertebrates-has been shown to scavenge superoxide anion produced in the heme pocket of the $\beta$-chain of $\mathrm{Hb}$ [9]. This reaction may be beneficial as it decreases the rate of $\mathrm{Hb}$ autoxidation and reduces heme degradation attributed to the reaction of superoxide with the heme [9]. The contribution of this $\mathrm{Hb}$ residue to erythrocyte antioxidant protection might be considerable because of its high concentration. Knock-in mouse models-in which erythrocytes contained wild-type human $\mathrm{Hb}$ or human $\mathrm{Hb}$ in which the $\beta 93$ cysteine residue was replaced with Alawere generated to directly explore the role of the conserved $\beta 93$ Cys [10]. While the authors did not observe hemolysis or hemolytic disorders in the $\beta 93 \mathrm{Ala}$ mice, they found that $\beta 93 \mathrm{Ala} \mathrm{Hb}$ has higher reactivity toward $\mathrm{H}_{2} \mathrm{O}_{2}$ than $\beta$ 93Cys $\mathrm{Hb}$ [11]. When $\beta 93 \mathrm{Ala} \mathrm{Hb}$ was reacted with $\mathrm{H}_{2} \mathrm{O}_{2}$, elevated formation of high molecular weight, presumably cross-linked $\mathrm{Hb}$ species were observed, suggesting that the $\beta 93 \mathrm{Cys}$ residue plays a protective role in the metabolism of reactive species produced by erythrocytes under stress conditions [11]. This notion was further supported by experiments in which oxidative stress was engendered in vivo in mice by challenging them with lipopolysaccharide (LPS). The authors found that LPS provoked more pronounced lung injury and a greater degree of hypotension in $\beta 93$ Ala versus $\beta 93$ Cys mice. These effects were accompanied by elevated level of erythrocyte reactive oxygen species [11].

Finally, the erythrocyte enzyme, NADH methemoglobin (MetHb) reductase (Aka diaphorase I) also contributes to the antioxidant network of the erythrocyte. Continuous exposure of erythrocyte $\mathrm{Hb}$ to oxygen leads to the oxidation of ferrous $\left(\mathrm{Fe}^{2+}\right)$ heme to ferric $\left(\mathrm{Fe}^{3+}\right)$ heme. The resulting MetHb is unable to carry oxygen. The function of MetHb reductase is to restore oxygen-binding ability of $\mathrm{Hb}$ by reducing ferric ion into ferrous ion (reviewed in [12]).

\section{Oxidation of $\mathbf{H b}$}

Under normal conditions, a very small amount of the oxygen attached to the $\mathrm{Hb}$ heme iron dissociates as superoxide anion leaving ferric heme. This explains why, in normal people, 1$2 \%$ of $\mathrm{Hb}$ is present as MetHb (1). Dismutation of superoxide anion by SODs generates $\mathrm{H}_{2} \mathrm{O}_{2}$. Numerous in vitro studies have been performed to describe the peroxide-mediated oxidation of $\mathrm{Hb}$ using purified human $\mathrm{Hb}$.

Peroxides like $\mathrm{H}_{2} \mathrm{O}_{2}$ may trigger a two-electron oxidation of $\mathrm{Hb}$ producing ferryl $\left(\mathrm{Fe}^{4+}=\mathrm{O}^{2-}\right) \mathrm{Hb}(2)$, whereas the reaction of $\mathrm{MetHb}$ with $\mathrm{H}_{2} \mathrm{O}_{2}$ yields ferrylHb radical $\left(\mathrm{Hb}^{\bullet+}\left(\mathrm{Fe}^{4+}=\mathrm{O}^{2-}\right)\right)$ in which the unpaired electron is associated with the globin or the porphyrin ring (3) [13-16]

$$
\begin{gathered}
\mathrm{Hb}\left(\mathrm{Fe}^{2+}\right) \mathrm{O}_{2} \longrightarrow \mathrm{Hb}\left(\mathrm{Fe}^{3+}\right)+\mathrm{O}_{2}^{--} \\
\mathrm{Hb}\left(\mathrm{Fe}^{2+}\right) \mathrm{O}_{2}+\mathrm{H}_{2} \mathrm{O}_{2} \longrightarrow \mathrm{Hb}\left(\mathrm{Fe}^{4+}=\mathrm{O}^{2-}\right)+\mathrm{H}_{2} \mathrm{O}+\mathrm{O}_{2} \\
\mathrm{Hb}\left(\mathrm{Fe}^{3+}\right)+\mathrm{H}_{2} \mathrm{O}_{2} \longrightarrow \mathrm{Hb}^{-+}\left(\mathrm{Fe}^{4+}=\mathrm{O}^{2-}\right)+\mathrm{H}_{2} \mathrm{O}
\end{gathered}
$$

The high-valence iron compounds are reactive intermediates and decay by several routes [17]. FerrylHb can initiate further production of globin radicals via an intramolecular electron transfer between the ferryl iron and specific amino acid residues of the globin chains resulting in the formation of MetHb globin radical (3). Radical/radical termination of globin- and porphyrin-centered radicals leads to the production of globin-globin (4) or porphyrin-globin crosslinks

$$
\begin{gathered}
\mathrm{Hb}\left(\mathrm{Fe}^{4+}=\mathrm{O}^{2-}\right)+2 \mathrm{H}^{+} \longrightarrow \mathrm{Hb}^{\bullet+}\left(\mathrm{Fe}^{3+}\right)+\mathrm{H}_{2} \mathrm{O} \\
\mathrm{Hb}^{\bullet+}\left(\mathrm{Fe}^{3+}\right)+\mathrm{Hb}^{\bullet+}\left(\mathrm{Fe}^{3+}\right) \longrightarrow\left(\mathrm{Fe}^{3+}\right){ }^{+} \mathrm{Hb}-\mathrm{Hb}^{+}\left(\mathrm{Fe}^{3+}\right)
\end{gathered}
$$

Considerable effort has been made to explore the mechanism via which the globin radicals are formed and where they are located within the protein. Several amino acids on both $\alpha$ - and $\beta$-globin chains were identified as targets of $\mathrm{H}_{2} \mathrm{O}_{2}$ triggered oxidation. When $\mathrm{Hb}$ was reacted with $\mathrm{H}_{2} \mathrm{O}_{2}$ in the presence of the spin trap 5,5-dimethyl-1-pyrroline $\mathrm{N}$ oxide (DMPO), several DMPO adducts were formed [18, 19]. Identification of the precise amino acid residues trapped by the DMPO by mass spectrometry revealed that radical formation occurs on $\beta$ Cys93, $\alpha$ Tyr24, $\alpha$ Tyr 42 , and $\alpha$ His-20 residues of the globin chains [18]. As part of this latter work, the authors showed that in the absence of a spin trap, the globin-centered radicals can decay by formation of crosslinks between the globin chains [18]. Later investigations identified key amino acids that appear to be highly susceptible to $\mathrm{H}_{2} \mathrm{O}_{2}$-mediated oxidation [15]. During $\mathrm{H}_{2} \mathrm{O}_{2}$-triggered $\mathrm{Hb}$ oxidation, $\beta$ Cys93 and $\beta$ Cys112 residues are irreversibly oxidized to cysteic acids, while oxidative modification of $\beta \operatorname{Trp}-15$ and $\beta$ Met-55 also occurs [15]. These processes might contribute to the loss of $\alpha$-helical structure of the $\beta$ chain surrounding the heme pocket and eventually lead to the deformation and collapse of the $\beta$ chains [15].

A number of studies have examined whether $\mathrm{H}_{2} \mathrm{O}_{2}$ mediated $\mathrm{Hb}$ oxidation occurs in intact erythrocytes despite the above-mentioned highly active antioxidant defense systems. Giulivi and Davies provided the first evidence for the formation of ferrylHb in intact red blood cells [20]. Later, the same group detected dityrosine in intact red blood 
cells exposed to $\mathrm{H}_{2} \mathrm{O}_{2}$ and provided a mechanism for its formation. They concluded that dityrosine is a hallmark of globin-centered tyrosyl radical formation and subsequent intermolecular cross-linking $[21,22]$.

Besides $\mathrm{H}_{2} \mathrm{O}_{2}$, oxidized lipids are very important triggers of $\mathrm{Hb}$ oxidation. For example, we showed that lipid hydroperoxides of atheroma lipids convert $\mathrm{Hb}$ to MetHb [23]. Furthermore, interactions between lipid hydroperoxides of oxLDL or atheroma lipids result in the formation of ferrylHb and covalently cross-linked $\mathrm{Hb}$ species [23].

3.1. Hb Oxidation In Vivo. Whether oxidation of $\mathrm{Hb}$ leading to the formation of high-valence heme/iron compounds and globin radicals occurs in vivo was a subject of debate until recently. These products are transiently formed and can initiate a range of oxidative reactions with similar reactivity to the hydroxyl radical. The first piece of evidence that the above-mentioned reactions occur in vivo came from the study of Svistunenko et al., in which the authors could detect ferrylHb globin-centered radicals in normal human blood by electron paramagnetic resonance spectroscopy [24]. Furthermore, covalently modified heme in $\mathrm{Hb}$ was detected by HPLC in normal human blood [25]. In the latter study, the authors showed that the concentration of covalently modified heme in $\mathrm{Hb}$ is increased by exercise, a surrogate model of acute oxidative stress [25].

Oxidation of $\mathrm{Hb}$ has been shown in certain pathological conditions. For example, heme-protein cross-linked $\mathrm{Hb}$ was detected in cerebrospinal fluid following subarachnoid hemorrhage by reverse phase HPLC [26]. Moreover, recently we found that the content of dityrosine is elevated and globinglobin cross-linked $\mathrm{Hb}$ multimers are present in complicated atherosclerotic lesions in humans [23].

\section{Control of Free $\mathrm{Hb}$ and Hb-Derived Heme}

Several pathological conditions are associated with hemolysis when $\mathrm{Hb}$ is released from erythrocytes into the extracellular milieu [27]. Extracellular $\mathrm{Hb}$ exerts vasoactive effects via scavenging nitric oxide, an important vasodilator and signaling molecule (reviewed in [27]). Moreover, oxidation of extracellular $\mathrm{Hb}$ triggers prooxidant (reviewed in [28]) and proinflammatory effects on vascular endothelium [29]. Efficient mechanisms have evolved for the removal of $\mathrm{Hb}$ from the circulation to control the deleterious effects of extracellular $\mathrm{Hb}$. Haptoglobin ( $\mathrm{Hp}$ ), an acute-phase protein, is present in plasma in high amounts $(0.41-1.65 \mathrm{mg} / \mathrm{mL})$ with the exclusive recognized function of capturing cell-free $\mathrm{Hb}$ and chaperoning $\mathrm{Hb}$ to macrophages for degradation (reviewed in [30]). Hp binding facilitates the removal of $\mathrm{Hb}$ from circulation through the CD163 macrophage scavenger receptor-mediated endocytosis [31] (Figure 1).

The formation of the $\mathrm{Hp}: \mathrm{Hb}$ complex is virtually irreversible, and $\mathrm{Hp}$ binding besides facilitating the removal of intravascular cell-free $\mathrm{Hb}$ has many additional beneficial effects. Several studies showed that $\mathrm{Hb}$ bound to $\mathrm{Hp}$ is less prone to $\mathrm{H}_{2} \mathrm{O}_{2}$-mediated oxidation than free $\mathrm{Hb}$ [32-34]. In fact, the Hb:Hp complex acts as a fairly efficient peroxidase
[35]. Further studies proved that $\mathrm{Hp}$ prevents $\mathrm{H}_{2} \mathrm{O}_{2}$-induced oxidation of amino acids in critical regions of $\mathrm{Hb}$ chainsthat is, $\alpha$ Tyr42, $\beta$ Tyr145, and $\beta$ Cys93-and polymerization of $\mathrm{Hb}$ [36]. The recent determination of the crystal structure of the porcine $\mathrm{Hp}: \mathrm{Hb}$ complex revealed that $\mathrm{Hb}$ residues known to be prone to oxidative modifications are buried in the $\mathrm{Hp}: \mathrm{Hb}$ interface, thereby explaining this direct protective role of $\mathrm{Hp}$ against $\mathrm{H}_{2} \mathrm{O}_{2}$-induced oxidation [37].

Following internalization by the macrophage, heme is cleaved by heme oxygenase-1 (HO-1) into biliverdin, carbon monoxide, and iron. This mechanism not only provides effective elimination of $\mathrm{Hb}$, but it also assures iron recycling for de novo erythropoiesis under normal circumstances. However, in cases of massive intravascular hemolysis, Hp can be depleted from the circulation in which the case of free $\mathrm{Hb}$ is cleared (rather inefficiently) via a low-affinity pathway through CD163 [38] and/or by renal excretion [39, 40]. This latter is accompanied by generation of free iron and organ damage.

The prooxidant effects of $\mathrm{Hb}$ are mainly attributed to heme release from oxidized $\mathrm{Hb}$. For example, MetHb but not $\mathrm{Hb}$ readily releases its heme prosthetic group which can be taken up by endothelial cells [41]. As a consequence of endothelial heme uptake, cells become extremely sensitive to oxidants like $\mathrm{H}_{2} \mathrm{O}_{2}$ or activated inflammatory cells [41]. Endothelial cells exposed to MetHb upregulate HO-1 and ferritin, key molecules responsible for heme degradation and safe storage of iron [41]. Heme release and subsequent endothelial reactions are efficiently blocked by Hp [41]. Heme transfer from oxidized $\mathrm{Hb}$ toward low-density lipoprotein (LDL) and consequent lipid peroxidation is also prevented by Hp [42] (Figure 1).

However, the protective effects of $\mathrm{Hp}$ are not entirely straightforward. In humans, the $\mathrm{Hp}$ gene is polymorphic resulting in the two functional alleles, that is, 1 and 2, which can form three different genotypes: Hp1-1, Hp2-1, and Hp22. Because $\mathrm{Hp} 1$ is monovalent and $\mathrm{Hp} 2$ is bivalent, the structures of protein products in the three genotypes show molecular heterogeneity. Hp1-1 is a small dimeric molecule $(86 \mathrm{kDa})$ whereas $\mathrm{Hp} 2-1$ is characterized by linear polymers (86-300 kDa) and Hp2-2 forms large cyclic polymers (170$900 \mathrm{kDa})$ (reviewed in [43]).

The Hp polymorphism was investigated as a possible genetic determinant in cardiovascular disease. These epidemiologic studies revealed that the Hp2-2 genotype is a risk factor for cardiovascular complications in both type I and type II diabetic patients (reviewed in [44]). Recently, it has been shown that Hp2-2 genotype is associated with elevated amounts of iron in atherosclerotic carotid plaques in diabetic patients [45] which may imply poor stabilization of free $\mathrm{Hb}$. The Hp2-2 genotype was found to be accompanied by increased macrophage infiltration and decreased smooth muscle cell content of the atherosclerotic plaque, two common indicators of plaque instability, in patients with diabetes [46]. In healthy men, Hp2-2 genotype is found to be associated with increased circulating oxLDL levels when compared to Hp1-1 or Hp2-1 genotypes [47]. Recently, the Hp2-2 genotype has been linked to greater risk of vasospasm and of clinical deterioration by delayed cerebral ischemia 


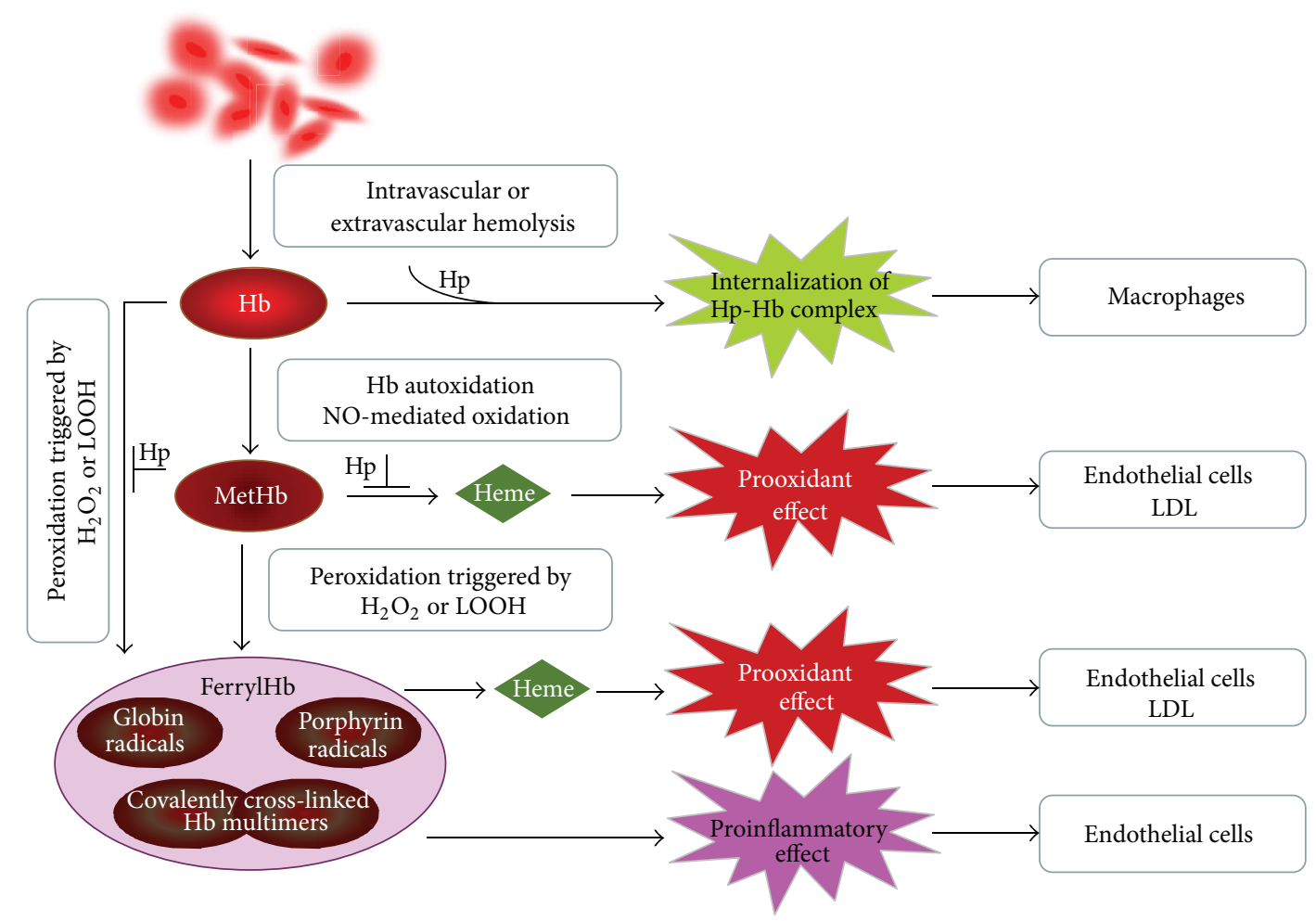

FIGURE 1: Schematic representation of hemoglobin oxidation and the different biological effects of oxidized Hb species. Hb is released from red blood cells following intra- or extravascular hemolysis. $\mathrm{Hb}$ can undergo spontaneous oxidation, or, alternatively, nitric oxide (NO) can trigger $\mathrm{Hb}$ oxidation to MetHb. Peroxidation of $\mathrm{Hb}$ and $\mathrm{MetHb}$ by $\mathrm{H}_{2} \mathrm{O}_{2}$ or lipid hydroperoxides ( $\mathrm{LOOH}$ ) leads to the formation of ferrylHb, that is, a mixture of globin radicals, porphyrin radicals, and covalently cross-linked $\mathrm{Hb}$ multimers. Haptoglobin (Hp) binds extracellular $\mathrm{Hb}$ and facilitates its internalization by macrophages. MetHb and ferrylHb can release heme and induce oxidative modification of lipids such as low-density lipoprotein (LDL), sensitizing cells to oxidant-mediated killing. FerrylHb is a proinflammatory agonist that targets endothelial cells. Heme release from oxidized $\mathrm{Hb}$ species and peroxidation of $\mathrm{Hb}$ are partially inhibited by $\mathrm{Hp}$.

following subarachnoid hemorrhage [48]. It has been shown that in preeclampsia, pathologies associated with elevated level of cell-free $\mathrm{Hb}, \mathrm{Hp} 2-1$, and $\mathrm{Hp} 2-2$ were associated with increased plasma heme levels and decreased plasma nitrite concentration [49].

Concomitant with these clinical observations, mechanical studies were performed in order to explain the molecular basis of these genetically determined differences. It has been demonstrated that Hp1-1 more efficiently inhibits heme transfer from MetHb to LDL compared to Hp2-2 [50, 51]. It has been reported that $\mathrm{Hp} 2-2: \mathrm{Hb}$ complex exhibits higher functional affinity for the macrophage scavenger receptor CD163 than the Hp1-1:Hb complex [31]. In contrast, Asleh et al. found that clearance rate of $\mathrm{Hp1}-\mathrm{1}: \mathrm{Hb}$ through CD163 is much higher than that of $\mathrm{Hp} 2-2: \mathrm{Hb}$ [52]. There are, as well, conflicting data concerning the different antioxidant properties and different $\mathrm{Hb}$ scavenging capacities of Hp11 and Hp2-2. In a recent publication, Lipiski et al. [53] did not find differences between Hp1-1 and Hp2-2 in $\mathrm{Hb}$ binding and intravascular compartmentalization in vivo. Furthermore, heme transfer from $\mathrm{Hb}$ to endothelial cells and LDL were equally blocked by Hp1-1 and Hp2-2 [53]. The apparent association of the Hp2-2 genotype with more severe symptoms in different pathologies might be explained by differences in size and penetration efficiency of Hp1-1 and Hp2-2. Because Hp2-2 is a large molecule, its diffusion into deeper compartments might be limited. Clearly, further investigations are warranted to improve our understanding of the molecular basis of the epidemiological and clinical findings related to the Hp polymorphism.

Oxidation of $\mathrm{Hb}$ leads to the formation of structurally altered (e.g., covalently cross-linked) $\mathrm{Hb}$ species. It was hypothesized that these structural changes might be associated with the impairment of the endogenous scavenging pathways. Recent studies have revealed that the elimination of oxidized $\mathrm{Hb}$ species via both high-affinity and low-affinity pathways can be severely compromised $[38,54]$.

Heme can be released from $\mathrm{Hb}$ upon oxidation. Hemopexin $(\mathrm{Hx})$ is an acute-phase plasma protein that binds heme with the highest affinity of any known protein [55]. Hx inhibits the catalytic activity of heme in oxidative reactions [56-58]. Hx-heme complexes are taken up via the scavenger receptor LDL receptor-related protein 1/CD91 [59]. Although CD91 is expressed by many different cell types, among them hepatocytes and macrophages in liver and spleen are the most important cells in scavenging the circulating $\mathrm{Hx}$-heme 
complexes [60]. Following endocytosis, heme is degraded by HO-1 and iron is stored by ferritin [61].

Hemoglobin and heme uptake pathways as well as heme degradation and iron storage mechanisms must function efficiently to control cell-free $\mathrm{Hb}$ - and heme-triggered cellular and organ damage and to limit renal iron exposure/loss during hemolysis or hemorrhage. Hp knock-out and Hx knockout mice suffer from oxidative renal injury and elevated iron loading in the kidney after a strong hemolytic stress $[62,63]$. Surprisingly, Hp/Hx double-null mice show reduced $\mathrm{Hb}$ accumulation in the kidney and improved survival after a lethal hemolytic stimulus [64]. This suggests that other, presently uncharacterized, protective mechanisms may be present in $\mathrm{Hp} / \mathrm{Hx}$ double-null mice which provide tolerance in hemolytic stress in a similar way as sickle hemoglobin confers tolerance to plasmodium infection [65].

\section{Biological Effects of Oxidized Hb}

5.1. Oxidized $\mathrm{Hb}$ as a Prooxidant. Iron compounds can facilitate the production of hydroxyl radicals from reactive oxygen species via the Fenton reaction. Sadrzadeh et al. hypothesized that $\mathrm{Hb}$ might provide catalytically active iron for the Fenton reaction and thus mediate hydroxyl radical generation [66]. They showed that $\mathrm{Hb}$ readily promotes hydroxyl radical formation in the presence of a superoxide anion-generating system [66]. They also examined the prooxidant effect of $\mathrm{Hb}$ on the central nervous system in vivo. They found that $\mathrm{Hb}$ injected into the spinal cord of cats mediates peroxidation of lipids in the central nervous system. The iron chelator desferrioxamine prevented the Hb-induced damage, suggesting that free iron derived from $\mathrm{Hb} /$ heme is the proximate toxic species [67].

Similarly, we later showed that MetHb but not Hb induces oxidative modification of LDL [42]. This effect of MetHb was inhibited by the heme-scavenging protein $\mathrm{Hx}$ and by $\mathrm{Hp}$ or cyanide, agents that either bind free heme or strengthen the heme-globin bond, highlighting the role of heme release in this process $[42,68]$. Recently, we showed that interactions between $\mathrm{Hb}$ and lipids derived from atheromatous lesions lead to a feed-forward process of $\mathrm{Hb}$ oxidation: conversion of oxyHb to MetHb, spontaneous heme release, oxidative heme lysis, iron release, and further lipid peroxidation [23]. We tested whether highly oxidized forms of $\mathrm{Hb}$ such as ferryl $\mathrm{Hb}$ might induce lipid peroxidation and found that ferrylHb like MetHb readily initiates oxidative modification of LDL and lipids from atheromatous lesions (Potor et al. unpublished observation) (Figure 1).

Transition metals, particularly iron, markedly potentiate oxidant damage to cells. Balla and coworkers showed that MetHb but not $\mathrm{Hb}$ synergizes damage from reactive oxygen species or activated inflammatory cell-mediated damage on vascular endothelial cells [41] (Figure 1). As might be expected, this effect of MetHb could be abrogated by the heme scavenger hemopexin or by strengthening the interaction between the heme and globin moieties, once again emphasizing the critical impact of heme release [41].
5.2. Oxidized Hb as an Inflammatory Mediator. Hemolytic or hemorrhagic episodes are often associated with inflammation even when infectious agents are absent [69]. Considerable effort has been made to define the mediators that trigger such inflammatory response. Endothelium, the interface between blood and tissue, has a pivotal role in the inflammatory response mainly by inducing the leukocyte adhesion cascade to facilitate the transmigration of inflammatory cells to the inflamed tissue. It has been shown that endothelial cells exposed to heme $(100 \mu \mathrm{mol} / \mathrm{L})$ upregulate the expression of adhesion molecules: intracellular adhesion molecule-1 (ICAM-1), vascular cell adhesion molecule-1 (VCAM-1), and E-selectin [70]. While searching for other mediators of hemolysis-associated inflammation, we found that ferrylHb but not native $\mathrm{Hb}$ or MetHb triggers the upregulation of the same proinflammatory adhesion molecules. [29] (Figure 1). In fact, ferrylHb seems to be a strong agonist of this inflammatory response, because it induces adhesion molecules at concentrations as low as $10 \mu \mathrm{mol} / \mathrm{L}$, a concentration at which heme has no effect. Endothelial cells exposed to ferrylHb show rearrangement of the actin cytoskeleton leading to disruption of the endothelial cell monolayer, intercellular gap formation, and increased permeability of the monolayer [29]. Actin polymerization is required for ferrylHb-induced inflammatory response and involves the activation of the c-Jun N-terminal kinase and the p38 mitogen-activated protein kinase signal transduction pathways [29]. Induction of inflammation is a unique property of the heavily oxidized ferrylHb because neither $\mathrm{Hb}$ nor MetHb triggers these effects [29] (Figure 1).

Heme itself has been shown to induce inflammation in mice [71]. In that work, mice were injected intravenously with heme to obtain $750-1000 \mu \mathrm{mol} / \mathrm{L}$ intravascular heme concentration $(\approx 55-75 \mu \mathrm{mol} / \mathrm{kg})$. Heme enhanced vascular permeability and increased leukocytes migration into inflammatory areas which was accompanied by the upregulation of the adhesion molecules in liver and pancreas [71]. Heme has been shown to be chemotactic for neutrophils when is injected into the peritoneal cavity of mice at a dose of only $2-20 \mu \mathrm{mol} / \mathrm{kg}$ [72]. We found that ferrylHb injected intraperitoneally to mice at a dose of $2 \mu \mathrm{mol} / \mathrm{kg}$ induced a robust inflammatory response leading to the recruitment of PMN cells in the peritoneum [29]. This effect was not observed when mice were challenged with $\mathrm{Hb}$ or MetHb [29].

Infectious diseases that cause hemolysis are among the most threatening human diseases. Recently, new mechanisms have been proposed which might help explain why the combination of hemolysis and infection is so dangerous. It has been shown that heme, released from oxidized $\mathrm{Hb}$ upon hemolysis, amplifies the innate immune response to microbial molecules such as LPS [73]. This effect of heme is dependent on the generation of reactive oxygen species [73]. Moreover, heme activates toll-like receptor 4 , a receptor of the innate immune system that recognizes pathogen-associated molecular patterns such as LPS [74]. In the last couple of years, heme has been implicated in different disease models (e.g., malaria and sepsis) as a molecule that can negatively modify the tolerance of the host to invading pathogens $[65,75-79]$. 
Overall, oxidized $\mathrm{Hb}$ appears to be a two-edged sword, with both edges unfortunately pointed in the wrong direction. Not only does free $\mathrm{Hb}$ promote oxidative damage triggered by exogenous and endogenous oxidants, but highly oxidized forms such as ferryl $\mathrm{Hb}$ also cause the upregulation of proinflammatory adhesion molecules. The net effect of such upregulation is the recruitment of inflammatory cells such as neutrophils and macrophages with resultant promotion of local inflammatory reactions. Teleologically, such responses to oxidized $\mathrm{Hb}$ may make sense; the presence of a hemorrhagic focus implies that the integument has been breached. Such an incident may permit the entry of adventitious bacteria, most of which can use $\mathrm{Hb}$ iron as fertilizer and with which they can grow rapidly [80]. In this light, it may be no surprise that $\mathrm{Hp}$ can suppress the $\mathrm{Hb}$ driven growth of pathogenic bacteria [44].

\section{Conclusions}

Our growing understanding of the pathophysiologic effects of extracellular $\mathrm{Hb}$ is leading to an improved understanding of normal and pathologic responses to various forms of $\mathrm{Hb}$ after release from red cells. For most of human history, the bruise was viewed as simply an interesting lesion, the color of which evolved over a period of days from red (red cells and some free oxyHb) to brown (lysed red cells, MetHb) to green/yellow (biliverdin/bilirubin). Now, it seems there may be more going on than meets the eye, especially the formation of different forms of oxidized $\mathrm{Hb}$ with varying biological activities. The complex system which has evolved to control and dispose of cell-free $\mathrm{Hb}$ generally works well unless overwhelmed by excessive hemorrhage or hemolysis. It is now becoming clear that cell-free, variously oxidized $\mathrm{Hb}$ is capable of promoting oxidation and inflammatory responses. This occurs through (1) the release of free heme (a toxic prooxidant molecule), (2) increasing expression of vascular adhesion molecules, and (3) the subsequent promotion of inflammatory processes. Fuller understanding of this chain of events may lead to the development of improved diagnostics and therapeutics meant to interrupt the pathologic effects of cell-free $\mathrm{Hb}$.

\section{Conflict of Interests}

The authors have no conflict of interests.

\section{Acknowledgments}

The research group is supported by the Hungarian Academy of Sciences (11003). This work was supported by Hungarian Government Grants OTKA-K75883 (György Balla), OTKAK83478 (József Balla), OTKA- PD83435 (Viktória Jeney), European Reintegration Grant FP7-PEOPLE-2010-268332 (Viktória Jeney), and by the TÁMOP-4.2.2.A-11/1/KONV2012-0045 and TÁMOP-4.2.2/B-10/1-2010-0024 Projects. The project is cofinanced by the European Union and the European Social Fund. It is also supported by the National
Institutes of Health (RO1AA018016) and the Commonwealth of Kentucky Research Challenge Trust Fund (John W. Eaton).

\section{References}

[1] W. G. Siems, O. Sommerburg, and T. Grune, "Erythrocyte free radical and energy metabolism," Clinical Nephrology, vol. 53, no. 1, pp. S9-S17, 2000.

[2] Y. S. Ho, J. L. Magnenat, R. T. Bronson et al., "Mice deficient in cellular glutathione peroxidase develop normally and show no increased sensitivity to hyperoxia," The Journal of Biological Chemistry, vol. 272, no. 26, pp. 16644-16651, 1997.

[3] Y.S. Ho, Y. Xiong, W. Ma, A. Spector, and D. S. Ho, "Mice lacking catalase develop normally but show differential sensitivity to oxidant tissue injury," The Journal of Biological Chemistry, vol. 279, no. 31, pp. 32804-32812, 2004.

[4] H. S. Jacob, S. H. Ingbar, and J. H. Jandl, "Oxidative hemolysis and erythrocyte metabolism in hereditary acatalasia," The Journal of Clinical Investigation, vol. 44, pp. 1187-1199, 1965.

[5] N. S. Agar, S. M. H. Sadrzadeh, P. E. Hallaway, and J. W. Eaton, "Erythrocyte catalase. A somatic oxidant defense?" The Journal of Clinical Investigation, vol. 77, no. 1, pp. 319-321, 1986.

[6] Y. Iuchi, F. Okada, K. Onuma et al., "Elevated oxidative stress in erythrocytes due to a SOD1 deficiency causes anaemia and triggers autoantibody production," Biochemical Journal, vol. 402, no. 2, pp. 219-227, 2007.

[7] C. A. Neumann, D. S. Krause, C. V. Carman et al., "Essential role for the peroxiredoxin Prdxl in erythrocyte antioxidant defence and tumour suppression," Nature, vol. 424, no. 6948, pp. 561$565,2003$.

[8] T. H. Lee, S. U. Kim, S. L. Yu et al., "Peroxiredoxin II is essential for sustaining life span of erythrocytes in mice," Blood, vol. 101, no. 12, pp. 5033-5038, 2003.

[9] C. Balagopalakrishna, O. O. Abugo, J. Horsky, P. T. Manoharan, E. Nagababu, and J. M. Rifkind, "Superoxide produced in the heme pocket of the $\beta$-chain of hemoglobin reacts with the $\beta$-93 cysteine to produce a thiyl radical," Biochemistry, vol. 37, no. 38, pp. 13194-13202, 1998.

[10] T. S. Isbell, C. W. Sun, L. C. Wu et al., "SNO-hemoglobin is not essential for red blood cell-dependent hypoxic vasodilation," Nature Medicine, vol. 14, no. 7, pp. 773-777, 2008.

[11] D. A. Vitturi, C. W. Sun, V. M. Harper et al., "Antioxidant functions for the hemoglobin beta93 cysteine residue in erythrocytes and in the vascular compartment in vivo," Free Radical Biology \& Medicine, vol. 55, pp. 119-129, 2013.

[12] M. J. Percy, N. V. McFerran, and T. R. J. Lappin, "Disorders of oxidised haemoglobin," Blood Reviews, vol. 19, no. 2, pp. 61-68, 2005.

[13] S. Harel and J. Kanner, "The generation of ferryl or hydroxyl radicals during interaction of haemproteins with hydrogen peroxide," Free Radical Research Communications, vol. 5, no. 1, pp. 21-33, 1988.

[14] R. P. Patel, D. A. Svistunenko, V. M. Darley-Usmar, M. C. R. Symons, and M. T. Wilson, "Redox cycling of human methaemoglobin by $\mathrm{H}_{2} \mathrm{O}_{2}$ yields persistent ferryl iron and protein based radicals," Free Radical Research, vol. 25, no. 2, pp. 117-123, 1996.

[15] Y. Jia, P. W. Buehler, R. A. Boykins, R. M. Venable, and A. I. Alayash, "Structural basis of peroxide-mediated changes in human hemoglobin: a novel oxidative pathway," The Journal of Biological Chemistry, vol. 282, no. 7, pp. 4894-4907, 2007. 
[16] A. I. Alayash, R. P. Patel, and R. E. Cashon, "Redox reactions of hemoglobin and myoglobin: biological and toxicological implications," Antioxidants and Redox Signaling, vol. 3, no. 2, pp. 313-327, 2001.

[17] B. J. Reeder, F. Cutruzzola, M. G. Bigotti, R. C. Hider, and M. T. Wilson, "Tyrosine as a redox-active center in electron transfer to ferryl heme in globins," Free Radical Biology and Medicine, vol. 44, no. 3, pp. 274-283, 2008.

[18] L. J. Deterding, D. C. Ramirez, J. R. Dubin, R. P. Mason, and K. B. Tomer, "Identification of free radicals on hemoglobin from its self-peroxidation using mass spectrometry and immunospin trapping: observation of a histidinyl radical," The Journal of Biological Chemistry, vol. 279, no. 12, pp. 11600-11607, 2004.

[19] D. C. Ramirez, Y. R. Chen, and R. P. Mason, "Immunochemical detection of hemoglobin-derived radicals formed by reaction with hydrogen peroxide: involvement of a protein-tyrosyl radical," Free Radical Biology and Medicine, vol. 34, no. 7, pp. 830839, 2003.

[20] C. Giulivi and K. J. A. Davies, "A novel antioxidant role for hemoglobin. The comproportionation of ferrylhemoglobin with oxyhemoglobin," The Journal of Biological Chemistry, vol. 265, no. 32, pp. 19453-19460, 1990.

[21] C. Giulivi and K. J. A. Davies, "Mechanism of the formation and proteolytic release of $\mathrm{H}_{2} \mathrm{O}_{2}$-induced dityrosine and tyrosine oxidation products in Hemoglobin and red blood cells," The Journal of Biological Chemistry, vol. 276, no. 26, pp. 2412924136, 2001.

[22] C. Giulivi and K. J. A. Davies, "Dityrosine and tyrosine oxidation products are endogenous markers for the selective proteolysis of oxidatively modified red blood cell hemoglobin by (the 19 S) proteasome," The Journal of Biological Chemistry, vol. 268, no. 12, pp. 8752-8759, 1993.

[23] E. Nagy, J. W. Eaton, V. Jeney et al., "Red cells, hemoglobin, heme, iron, and atherogenesis," Arteriosclerosis, Thrombosis, and Vascular Biology, vol. 30, no. 7, pp. 1347-1353, 2010.

[24] D. A. Svistunenko, R. P. Patel, S. V. Voloshchenko, and M. T. Wilson, "The globin-based free radical of ferryl hemoglobin is detected in normal human blood," The Journal of Biological Chemistry, vol. 272, no. 11, pp. 7114-7121, 1997.

[25] N. B. J. Vollaard, B. J. Reeder, J. P. Shearman, P. Menu, M. T. Wilson, and C. E. Cooper, "A new sensitive assay reveals that hemoglobin is oxidatively modified in vivo," Free Radical Biology and Medicine, vol. 39, no. 9, pp. 1216-1228, 2005.

[26] B. J. Reeder, M. A. Sharpe, A. D. Kay, M. Kerr, K. Moore, and M. T. Wilson, "Toxicity of myoglobin and haemoglobin: oxidative stress in patients with rhabdomyolysis and subarachnoid haemorrhage," Biochemical Society Transactions, vol. 30, no. 4, pp. 745-748, 2002.

[27] R. P. Rother, L. Bell, P. Hillmen, and M. T. Gladwin, “The clinical sequelae of intravascular hemolysis and extracellular plasma hemoglobin: a novel mechanism of human disease," Journal of the American Medical Association, vol. 293, no. 13, pp. 16531662, 2005.

[28] J. Balla, G. M. Vercellotti, V. Jeney et al., "Heme, heme oxygenase and ferritin in vascular endothelial cell injury," Molecular Nutrition and Food Research, vol. 49, no. 11, pp. 1030-1043, 2005.

[29] G. Silva, V. Jeney, A. Chora, R. Larsen, J. Balla, and M. P. Soares, "Oxidized hemoglobin is an endogenous proinflammatory agonist that targets vascular endothelial cells," The Journal of Biological Chemistry, vol. 284, no. 43, pp. 29582-29595, 2009.

[30] A. I. Alayash, "Haptoglobin: old protein with new functions," Clinica Chimica Acta, vol. 412, no. 7-8, pp. 493-498, 2011.
[31] M. Kristiansen, J. H. Graversen, C. Jacobsen et al., "Identification of the haemoglobin scavenger receptor," Nature, vol. 409, no. 6817, pp. 198-201, 2001.

[32] P. W. Buehler, B. Abraham, F. Vallelian et al., "Haptoglobin preserves the CD163 hemoglobin scavenger pathway by shielding hemoglobin from peroxidative modification," Blood, vol. 113, no. 11, pp. 2578-2586, 2009.

[33] S. Banerjee, Y. Jia, C. J. Siburt et al., "Haptoglobin alters oxygenation and oxidation of hemoglobin and decreases propagation of peroxide-induced oxidative reactions," Free Radical Biology \& Medicine, vol. 53, pp. 1317-1326, 2012.

[34] Y. I. Miller, S. M. Altamentova, and N. Shaklai, "Oxidation of low-density lipoprotein by hemoglobin stems from a heineinitiated globin radical: antioxidant role of haptoglobin," Biochemistry, vol. 36, no. 40, pp. 12189-12198, 1997.

[35] A. Kapralov, I. I. Vlasova, W. Feng et al., "Peroxidase activity of hemoglobin'haptoglobin complexes. Covalent aggreation and oxidative stress in plasma and macrophages," The Journal of Biological Chemistry, vol. 284, no. 44, pp. 30395-30407, 2009.

[36] T. Pimenova, C. P. Pereira, P. Gehrig, P. W. Buehler, D. J. Schaer, and R. Zenobi, "Quantitative mass spectrometry defines an oxidative hotspot in hemoglobin that is specifically protected by haptoglobin," Journal of Proteome Research, vol. 9, no. 8, pp. 4061-4070, 2010.

[37] C. B. Andersen, M. Torvund-Jensen, M. J. Nielsen et al., "Structure of the haptoglobin-haemoglobin complex," Nature, vol. 489, pp. 456-459, 2012.

[38] D. J. Schaer, C. A. Schaer, P. W. Buehler et al., "CD163 is the macrophage scavenger receptor for native and chemically modified hemoglobins in the absence of haptoglobin," Blood, vol. 107, no. 1, pp. 373-380, 2006.

[39] D. J. Schaer, P. W. Buehler, A. I. Alayash, J. D. Belcher, Vercellotti, and G. M. Hemolysis a, "nd free hemoglobin revisited: exploring hemoglobin and hemin scavengers as a novel class of therapeutic proteins," Blood, vol. 121, pp. 1276-1284, 2013.

[40] R. K. Murray, G. E. Connell, and J. H. Pert, "The role of haptoglobin in the clearance and distribution of extracorpuscular hemoglobin," Blood, vol. 17, pp. 45-53, 1961.

[41] J. Balla, H. S. Jacob, G. Balla, K. Nath, J. W. Eaton, and G. M. Vercellotti, "Endothelial-cell heme uptake from heme proteins: Induction of sensitization and desensitization to oxidant damage," Proceedings of the National Academy of Sciences of the United States of America, vol. 90, no. 20, pp. 9285-9289, 1993.

[42] V. Jeney, J. Balla, A. Yachie et al., "Pro-oxidant and cytotoxic effects of circulating heme," Blood, vol. 100, no. 3, pp. 879-887, 2002.

[43] H. Goldenstein, N. S. Levy, and A. P. Levy, "Haptoglobin genotype and its role in determining heme-iron mediated vascular disease," Pharmacological Research, vol. 66, pp. 1-6, 2012.

[44] T. Costacou and A. P. Levy, "Haptoglobin genotype and its role in diabetic cardiovascular disease," Journal of Cardiovascular Translational Research, vol. 5, pp. 423-435, 2012.

[45] C. Lioupis, C. Barbatis, A. Drougou et al., "Association of haptoglobin genotype and common cardiovascular risk factors with the amount of iron in atherosclerotic carotid plaques," Atherosclerosis, vol. 216, no. 1, pp. 131-138, 2011.

[46] C. Lioupis, C. Barbatis, P. Lazari et al., "Macrophage infiltration and smooth muscle cells content associated with haptoglobin genotype in human atherosclerotic carotid plaques," Angiology, vol. 63, pp. 178-183, 2012. 
[47] A. Brouwers, M. Langlois, J. Delanghe et al., "Oxidized lowdensity lipoprotein, iron stores, and haptoglobin polymorphism," Atherosclerosis, vol. 176, no. 1, pp. 189-195, 2004.

[48] H. Ohnishi, K. Iihara, Y. Kaku et al., "Haptoglobin phenotype predicts cerebral vasospasm and clinical deterioration after aneurysmal subarachnoid hemorrhage," Journal of Stroke and Cerebrovascular Diseases, 2013.

[49] V. C. Sandrim, A. C. T. Palei, J. T. Sertorio, R. C. Cavalli, G. Duarte, and J. E. Tanus-Santos, "Effects of eNOS polymorphisms on nitric oxide formation in healthy pregnancy and in pre-eclampsia," Molecular Human Reproduction, vol. 16, no. 7, Article ID gaq030, pp. 506-510, 2010.

[50] V. V. Bamm, V. A. Tsemakhovich, M. Shaklai, and N. Shaklai, "Haptoglobin phenotypes differ in their ability to inhibit heme transfer from hemoglobin to LDL," Biochemistry, vol. 43, no. 13, pp. 3899-3906, 2004.

[51] M. Melamed-Frank, O. Lache, B. I. Enav et al., "Structurefunction analysis of the antioxidant properties of haptoglobin," Blood, vol. 98, no. 13, pp. 3693-3698, 2001.

[52] R. Asleh, S. Marsh, M. Shilkrut et al., "Genetically determined heterogeneity in hemoglobin scavenging and susceptibility to diabetic cardiovascular disease," Circulation Research, vol. 92, no. 11, pp. 1193-1200, 2003.

[53] M. Lipiski, J. W. Deuel, J. H. Baek, W. R. Engelsberger, P. W. Buehler, and D. J. Schaer, "Human Hp1-1 and Hp2-2 phenotypespecific haptoglobin therapeutics are both effective in vitro and in guinea pigs to attenuate hemoglobin toxicity," Antioxidants \& Redox Signaling, 2013.

[54] F. Vallelian, T. Pimenova, C. P. Pereira et al., "The reaction of hydrogen peroxide with hemoglobin induces extensive $\alpha$ globin crosslinking and impairs the interaction of hemoglobin with endogenous scavenger pathways," Free Radical Biology and Medicine, vol. 45, no. 8, pp. 1150-1158, 2008.

[55] Z. Hrkal, Z. Vodrazka, and I. Kalousek, "Transfer of heme from ferrihemoglobin and ferrihemoglobin isolated chains to hemopexin," European Journal of Biochemistry, vol. 43, no. 1, pp. 73-78, 1974.

[56] J. M. C. Gutteridge and A. Smith, "Antioxidant protection by haemopexin of haem-stimulated lipid peroxidation," Biochemical Journal, vol. 256, no. 3, pp. 861-865, 1988.

[57] S. H. Vincent, R. W. Grady, N. Shaklai, J. M. Snider, and U. Muller-Eberhard, "The influence of heme-binding proteins in heme-catalyzed oxidations," Archives of Biochemistry and Biophysics, vol. 265, no. 2, pp. 539-550, 1988.

[58] G. Balla, H. S. Jacob, J. W. Eaton, J. D. Belcher, and G. M. Vercellotti, "Hemin: a possible physiological mediator of low density lipoprotein oxidation and endothelial injury," Arteriosclerosis and Thrombosis, vol. 11, no. 6, pp. 1700-1711, 1991.

[59] V. Hvidberg, M. B. Maniecki, C. Jacobsen, P. Højrup, H. J. Møller, and S. K. Moestrup, "Identification of the receptor scavenging hemopexin-heme complexes," Blood, vol. 106, no. 7, pp. 2572-2579, 2005.

[60] J. Herz and D. K. Strickland, "LRP: a multifunctional scavenger and signaling receptor," The Journal of Clinical Investigation, vol. 108, no. 6, pp. 779-784, 2001.

[61] J. Alam and A. Smith, "Receptor-mediated transport of heme by hemopexin regulates gene expression in mammalian cells," The Journal of Biological Chemistry, vol. 264, no. 30, pp. 1763717640, 1989.

[62] S. Fagoonee, J. Gburek, E. Hirsch et al., "Plasma protein haptoglobin modulates renal iron loading," American Journal of Pathology, vol. 166, no. 4, pp. 973-983, 2005.
[63] E. Tolosano, E. Hirsch, E. Patrucco et al., "Defective recovery and severe renal damage after acute hemolysis in hemopexindeficient mice," Blood, vol. 94, no. 11, pp. 3906-3914, 1999.

[64] E. Tolosano, S. Fagoonee, E. Hirsch et al., "Enhanced splenomegaly and severe liver inflammation in haptoglobin/ hemopexin double-null mice after acute hemolysis," Blood, vol. 100, no. 12, pp. 4201-4208, 2002.

[65] A. Ferreira, I. Marguti, I. Bechmann et al., "Sickle hemoglobin confers tolerance to plasmodium infection," Cell, vol. 145, no. 3, pp. 398-409, 2011.

[66] S. M. H. Sadrzadeh, E. Graf, and S. S. Panter, "Hemoglobin. A biologic Fenton reagent," The Journal of Biological Chemistry, vol. 259, no. 23, pp. 14354-14356, 1984.

[67] S. M. H. Sadrzadeh, D. K. Anderson, and S. S. Panter, "Hemoglobin potentiates central nervous system damage," The Journal of Clinical Investigation, vol. 79, no. 2, pp. 662-664, 1987.

[68] Y. I. Miller, A. Smith, W. T. Morgan, and N. Shaklai, "Role of hemopexin in protection of low-density lipoprotein against hemoglobin-induced oxidation," Biochemistry, vol. 35, no. 40, pp. 13112-13117, 1996.

[69] M. A. Arruda, A. V. Graça-Souza, and C. Barja-Fidalgo, "Heme and innate immunity: new insights for an old molecule," Memorias do Instituto Oswaldo Cruz, vol. 100, no. 7, pp. 799803, 2005.

[70] F. A. D. T. G. Wagener, E. Feldman, T. De Witte, and N. G. Abraham, "Heme induces the expression of adhesion molecules ICAM-1, VCAM-1, and E selectin in vascular endothelial cells," Experimental Biology and Medicine, vol. 216, no. 3, pp. 456-463, 1997.

[71] F. A. D. T. G. Wagener, A. Eggert, O. C. Boerman et al., "Heme is a potent inducer of inflammation in mice and is counteracted by heme oxygenase," Blood, vol. 98, no. 6, pp. 1802-1811, 2001.

[72] B. N. Porto, L. S. Alves, P. L. Fernández et al., "Heme induces neutrophil migration and reactive oxygen species generation through signaling pathways characteristic of chemotactic receptors," The Journal of Biological Chemistry, vol. 282, no. 33, pp. 24430-24436, 2007.

[73] P. L. Fernandez, F. F. Dutra, L. Alves et al., "Heme amplifies the innate immune response to microbial molecules through spleen tyrosine kinase (Syk)-dependent reactive oxygen species generation," The Journal of Biological Chemistry, vol. 285, no. 43, pp. 32844-32851, 2010.

[74] R. T. Figueiredo, P. L. Fernandez, D. S. Mourao-Sa et al., "Characterization of heme as activator of toll-like receptor 4," The Journal of Biological Chemistry, vol. 282, no. 28, pp. 2022120229, 2007.

[75] R. Larsen, R. Gozzelino, V. Jeney et al., "A central role for free heme in the pathogenesis of severe sepsis," Science Translational Medicine, vol. 2, no. 51, Article ID 51ra71, 2010.

[76] A. Ferreira, J. Balla, V. Jeney, G. Balla, and M. P. Soares, “A central role for free heme in the pathogenesis of severe malaria: the missing link?" Journal of Molecular Medicine, vol. 86, no. 10, pp. 1097-1111, 2008.

[77] A. Pamplona, A. Ferreira, J. Balla et al., "Heme oxygenase-1 and carbon monoxide suppress the pathogenesis of experimental cerebral malaria," Nature Medicine, vol. 13, no. 6, pp. 703-710, 2007.

[78] E. Seixas, R. Gozzelino, A. Chora et al., "Heme oxygenase-1 affords protection against noncerebral forms of severe malaria," Proceedings of the National Academy of Sciences of the United States of America, vol. 106, no. 37, pp. 15837-15842, 2009. 
[79] R. Gozzelino, B. B. Andrade, R. Larsen et al., "Metabolic adaptation to tissue iron overload confers tolerance to malaria," Cell Host \& Microbe, vol. 12, pp. 693-704, 2012.

[80] S. Telang, E. Vimr, J. R. Mahoney et al., "Strain-specific irondependent virulence in Escherichia coli," Journal of Infectious Diseases, vol. 184, no. 2, pp. 159-165, 2001. 


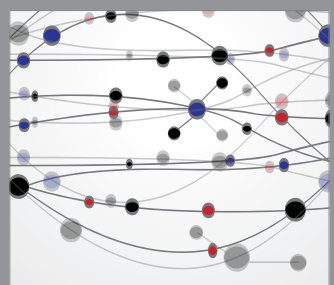

The Scientific World Journal
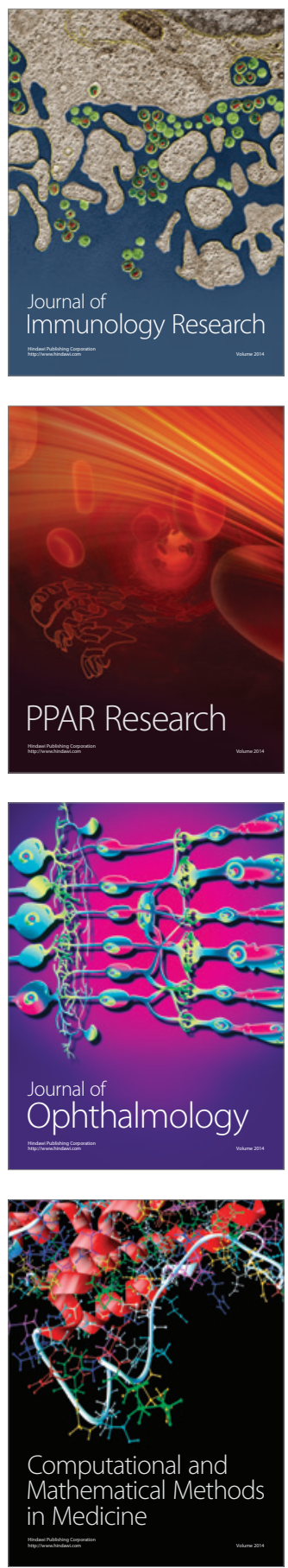

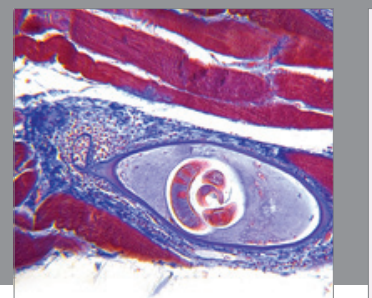

Gastroenterology

Research and Practice
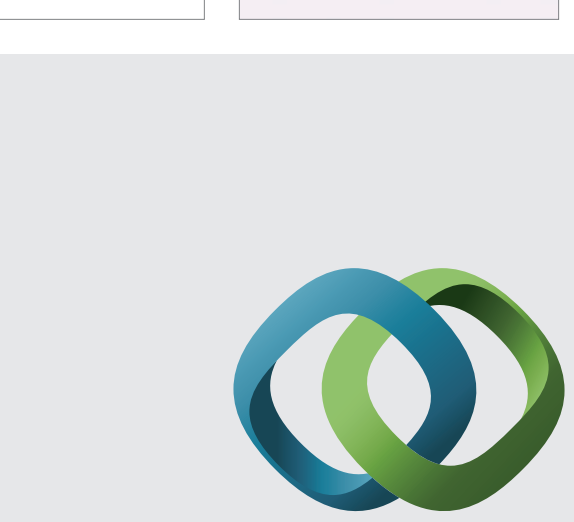

\section{Hindawi}

Submit your manuscripts at

http://www.hindawi.com
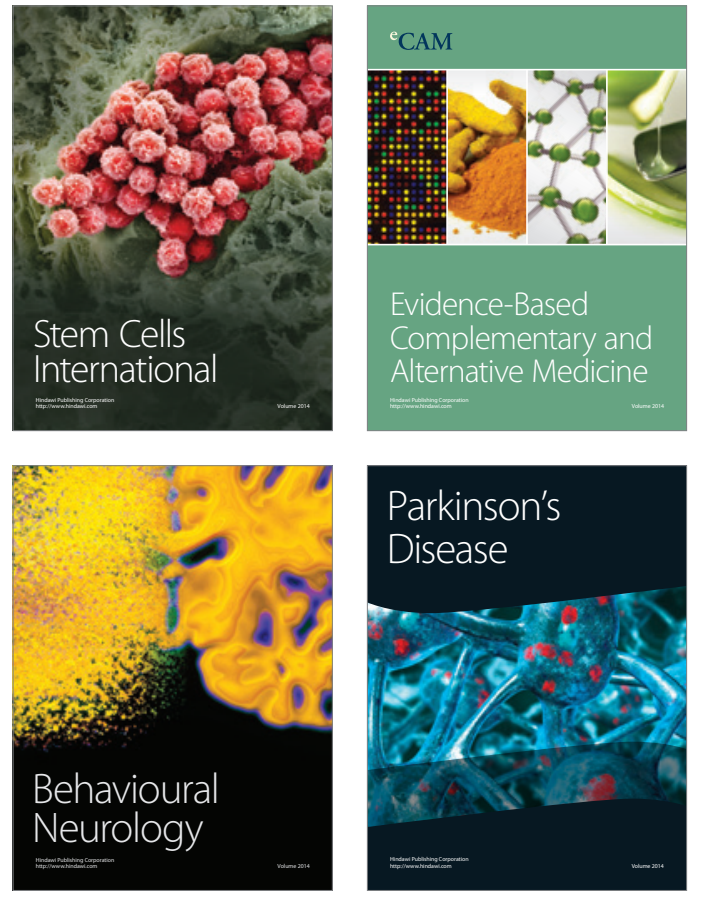
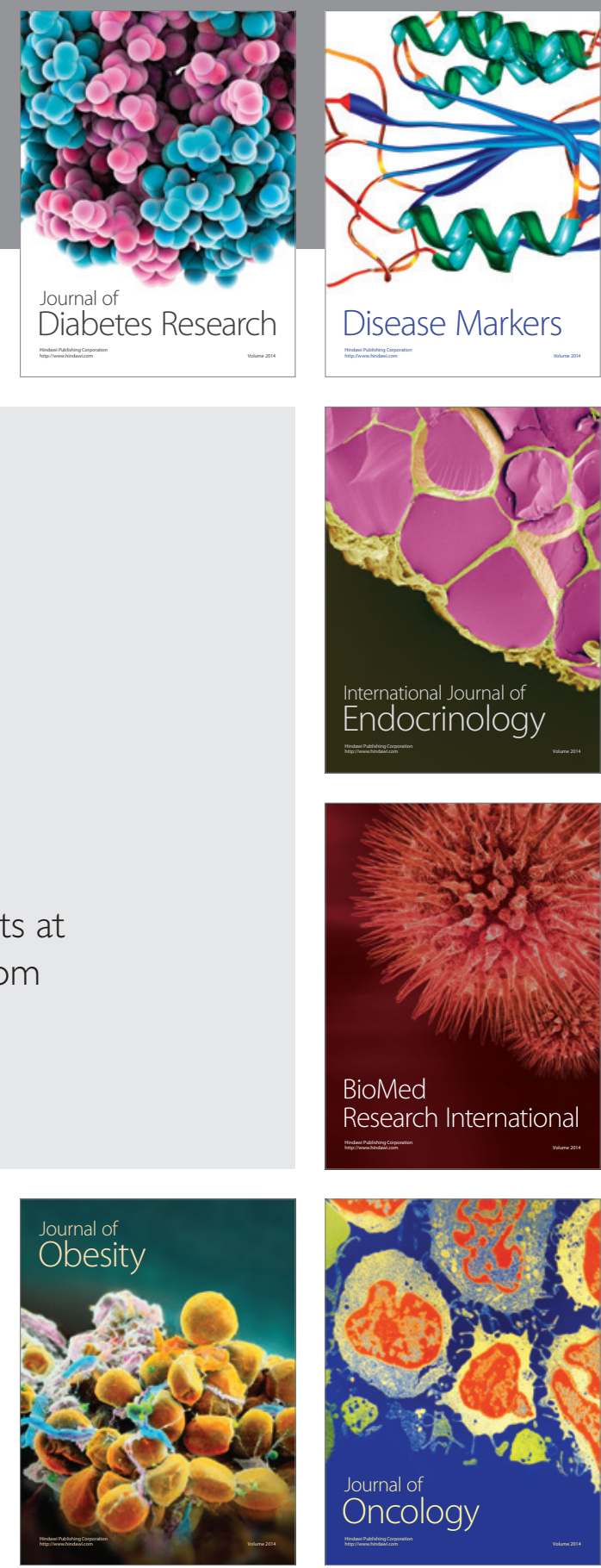

Disease Markers
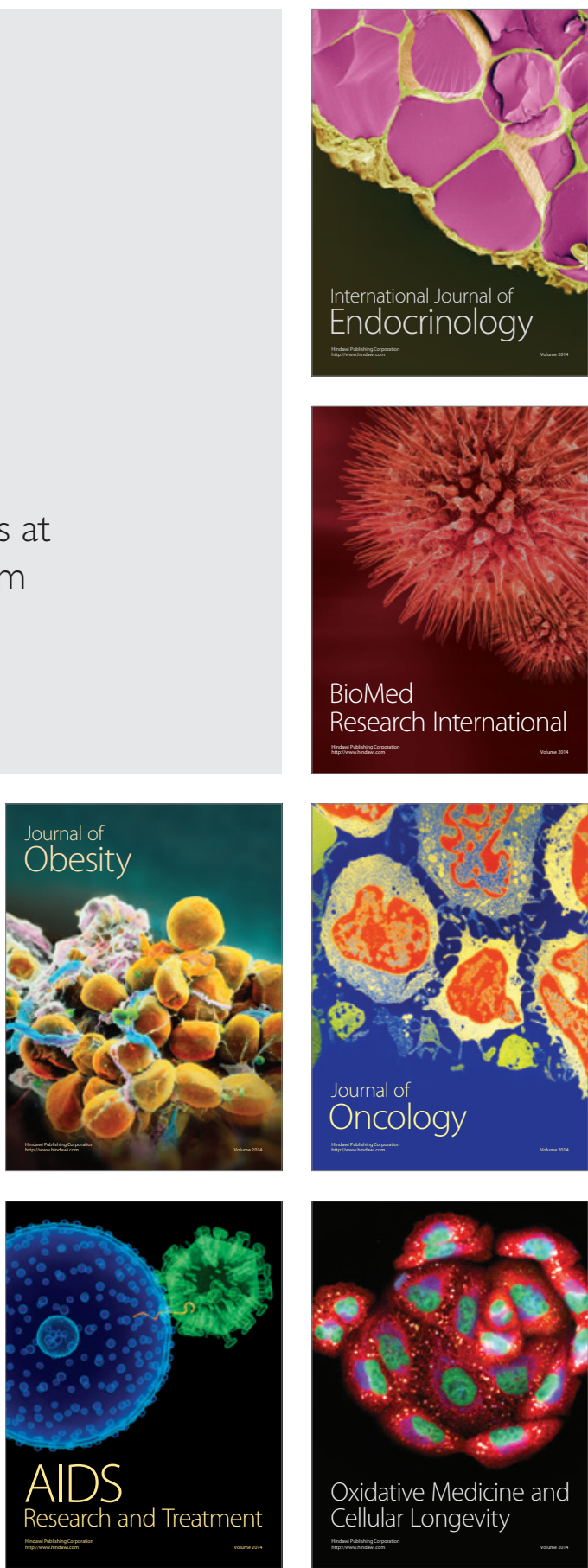